\title{
Endovascular Management of a Ruptured Arteriovenous Malformation in a Pregnant Woman: A Case Report
}

\author{
Sirakov A. ${ }^{1}$, Matanov Sv. ${ }^{2}$, Dineva $\mathrm{Sv}^{3}$ \\ UH St. Ivan Rilski- Sofia
}

\begin{abstract}
Ruptured intracranial arteriovenous malformation (AVM) in pregnancy is a rare and complex situation. Due to its unique rarity, no definitive guidelines exist to this date. Endovascular embolization is widely accepted as an important component in the multidisciplinary therapy for this pathology. However, unrupturedarteriovenous malformations in pregnant woman generally warrant conservative management due to the low rupture risk.
\end{abstract}

Keywords: Arteriovenous malformation, embolization, pregnancy

\section{Case Presentation}

A 25-year-old woman was presented to our institution with "thunderclap" headache, vomiting, neck stiffness and CTA data of a ruptured left frontal arteriovenous malformation in the 12th week of her pregnancy. Taking in to account the high-risk from ionizing radiation the patient's relatives were informed sufficiently and a single stage of endovascular embolization was scheduled. The main goal was to better understand the anatomy of the malformation, to observe for intra-nidal aneurysms and to totally embolize the AVM via the safely-accessible feeders.

\section{Introduction}

Cerebral arteriovenousmal formation (AVM) are relatively rare and complex cerebral lesions. Pregnancy and coexisting intracranial AVM is a complex and dangerous situation and may have fatal consequences. (1). A correlation between the nidal rupture and pregnancy has been proposed and it may be caused by the increased cardiac output or elevated estrogen levels. Recently, a study reported the rate of intracranial hemorrhage from AVM was $8.1 \%$ per pregnancy, higher than the usual rate of rupture in female patients coexisting with cerebral AVM. The re-bleedings in pregnant women are also associated with high maternal and fetal mortality $-10 \%$ to $40 \%$.

Recent reports suggest that ruptured AVM presented during pregnancy have been managed surgically with sufficient results. (2) Thus, despite the potential teratogenic effects of anesthetic agents and the radiation on the fetus the debate for most safety and appropriate approach is still ongoing. (3)

With the latest advances in the endovascular technology, embolization of cerebral arteriovenous malformations has been used widely over to microsurgery with much reported success. $(5,6,8)$ However, to this date the role of the endovascular approach in management of symptomatic AVM during pregnancy has not been well established.

\section{Case report}

D.D a 25- year old woman, 15 weeks into her first pregnancy was presented to our hospital with sudden onset of "thunderclap" headache associated with vomiting and neck stiffness. A CT angiography was performed in an outside hospital with data intracranial hemorrhage FISHER IV due to a ruptured left frontal arteriovenous malformation with intra-nidal aneurysm. Her past medical history was significant for an alcohol and cigarette abuse. Our patient's physical exam showed he presence of meningeal irritation.

A multidisciplinary team of neurosurgeons and radiologist informed the patient and her present relatives about the situation and the potential risk of re-rupture a decision for performing an endovascular embolization of the ruptured AVM was made.

The procedure was coordinated with anesthesiologist to ensure the safety of both the mother and the fetus. During the procedure measures were taken to reduce the exposure of the fetus to ionizing radiation to a minimum.

After Seldinger catheterization of the right femoral artery, a digital preoperative panangiography was performed to determine the anatomy of the AVM and its feeders and venous drainage. 


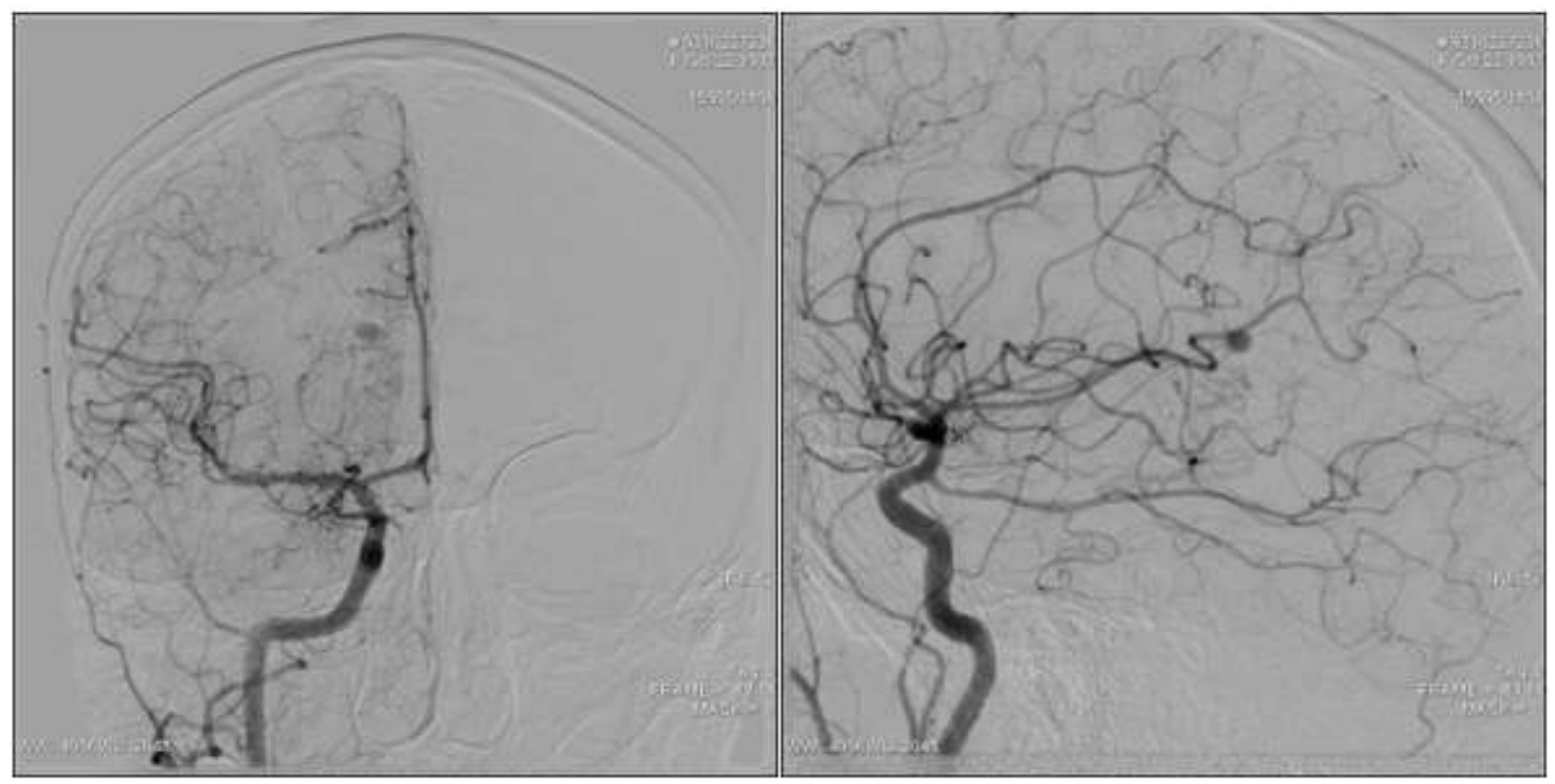

Figure 1: Angiogram of left ICA, showing AVM with intranidal aneurysm

The guide catheter was positioned in the distal left internal carotid artery. A microcatheter with detachable tip was navigated over a guide wire to select the inferior division of the left pericalosal artery feeding the AVM.
After few contrast injections and ensuring that the selected branch was feeding the nidus, Onyx-18 (Onyx Liquid Embolic System ${ }^{\circledR}$ ) application was initiated.

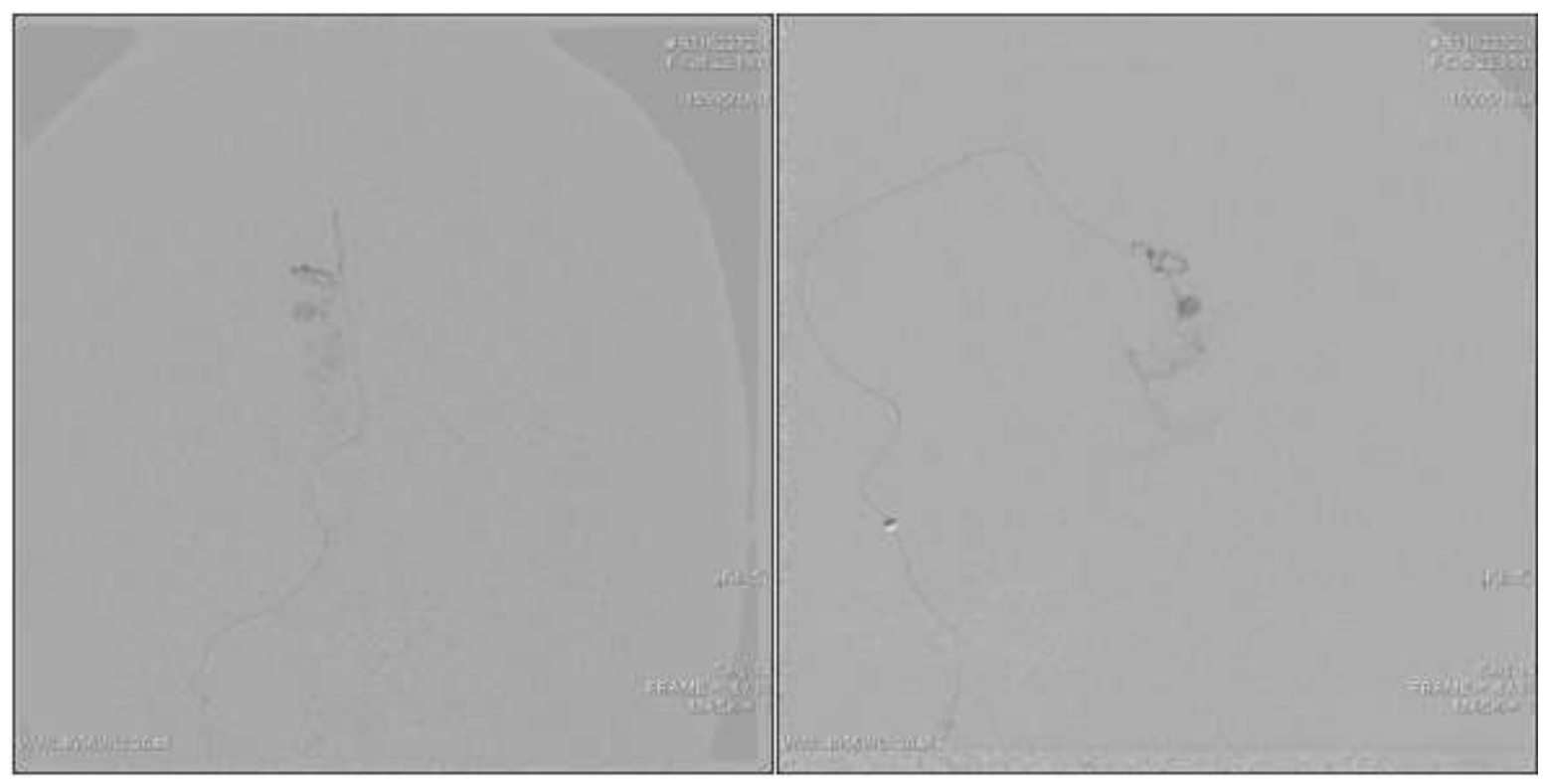

Figure 2: Superselective angiography showing the nidus and the aneurysm

Control angio after the embolization showed a complete

obliteration of the nidus with preserving venous outflow.

Volume 6 Issue 12, December 2017

www.ijsr.net

Licensed Under Creative Commons Attribution CC BY 


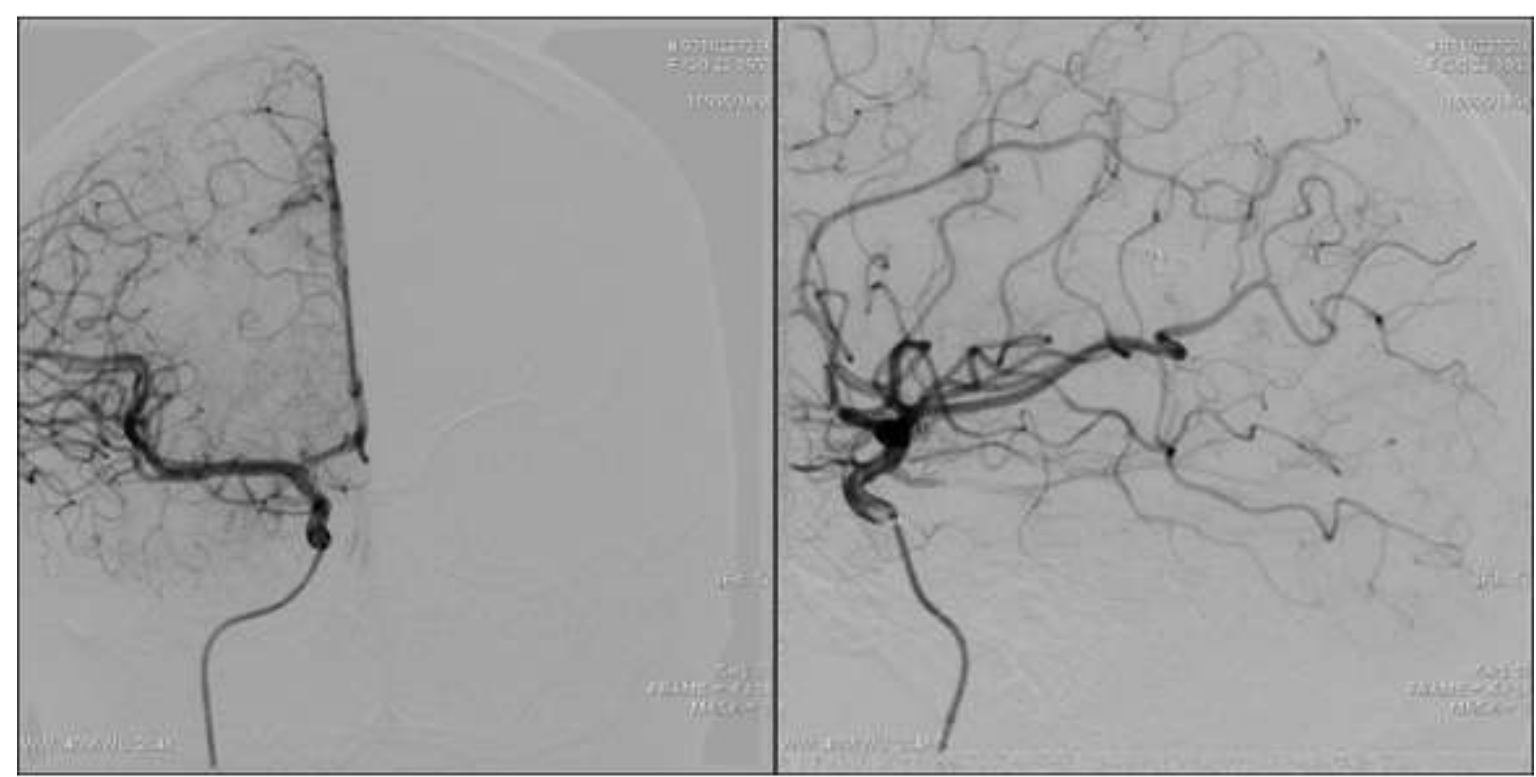

Figure 3: Control angio at the end of the procedure, showing no filing of the pathological nidus

After the procedure, procedure the patient was transferred to the intensive care unit for close observation due to presence of intracranial hemorrhage. An uncomplicated postoperative course with no additional neurological deficit was recorded at patients discharge.

Under lead shielding protection, the exposure dose after head CT scanning and cerebral angiography was $0.025 \mathrm{mGy}$. However, considering the potential biological effect of the radiation the patient chose abortion after extensive counseling.

\section{Discussion}

Emergency operation is necessary for ruptured cerebral AVM in pregnancy. Intracranial hematoma and subarachnoid hemorrhage can cause worsening neurological symptoms, cerebral ischemia or even death for the mother and the fetus. Cesarean section is indicated if the fetus is mature enough. In the case where the fetus was not mature, the risk of AVM re -bleeding is increasing a surgical excision or endovascular embolization could be performed.

Endovascular approaches for ruptured cerebral AVM in pregnancy should be performed according with angiographic and anatomy features. Radioactive diagnosis and treatment methods should be avoided during pregnancy unless they are necessary. With the recent technological advances of the endovascular methods, several case reports suggest that endovascular embolization is safe and effective in the period of pregnancy for ruptured cerebral arteriovenous malformations and aneurysms. In these cases, the proper shielding of the abdomen and minimizing the use of ionizing radiation are of particular importance.

However, for lesions in easily accessible areas, surgery alone may be suitable. When the target lesions are in deep brain areas or have many fragile feeders, embolization may increase the cure rate. Onyx embolization system and Visipaque contrast agents are not contraindicated in pregnancy. Finally, for better maternal and fetal prognosis, future studiesand guidelines for female patients with unruptured or ruptured cerebral AVMs should be established.

\section{Conclusion}

Ruptured cerebral arteriovenous malformation during pregnancy is a serious situation and should be actively treated. Particularly when safety measures are taken in account to protect the fetus endovascular embolization can provide a safe and proper management of this rare condition.

\section{References}

[1] Perquin DA, Kloet A, Tans JT, Witte GN, Dörr PJ. Intracranial arteriovenous malformations in pregnant women. Ned TijdschrGeneeskd. 1999;143:497-500.

[2] SirakovS., KamenovB., PenkovM., MarinovM. Clinical case of a complex arteriovenous malformation. BulgNeurosurg, 2014 ,19 (1-2)

[3] Fujita K, Tsunoda H, Shigemitsu S, Kubo T. Clinical study on the intracranial arteriovenous malformation associated with pregnancy. Nippon SankaFujinkaGakkaiZasshi. 1995;47:1359-1364.

[4] Sirakov S., Kamenov B.,Penkov M., MarinovM. Double lumen balloon catheter in arteriovenous malformation embolization using Onyx Roentgenologia\&Radiologia, 2015, LIV: 122-125

[5] Trivedi RA, Kirkpatrick PJ. Arteriovenous malformations of the cerebral circulation that rupture in pregnancy. J ObstetGynaecol. 2003;23:484-488. doi:10.1080/0144361031000153684.

[6] SirakovS. Arterio-venous malformation - classification, imaging and endovascular treatment. Roentgenologia\&Radiologia, 2015, LIV:86-96

[7] SirakovS. , BuchvarovCh. , PenkovM., SirakovA., KamenovB., TodorovY., NinovK., Transvenous embolization of indirect carotid-cavernous fistula via upper ophthalmic/facial vein - case report and literature review. Roentgenologia \& Radiologia, 2015, LIV : 242246

\section{Volume 6 Issue 12, December 2017}




\section{International Journal of Science and Research (IJSR) \\ ISSN (Online): 2319-7064}

Index Copernicus Value (2016): 79.57 | Impact Factor (2015): 6.391

[8] Schwartz J, Lynbrook NY. Pregnancy complicated by subarachnoid hemorrhage. Am J Obstet Gynecol. 1951;62:539-547.

[9] Robinson JL, Hall CS, Sedzimir CB. Subarachnoid hemorrhage in pregnancy. J Neurosurg. 1972;36:27-33. doi: 10.3171/jns.1972.36.1.0027.

[10] Sirakov S., Penkov M. , Sirakov A. , Minkin K. , Ninov K. Preoperative Embolization of Hemangioblastomas International Journal of Science and Research (IJSR), Volume 6 Issue 1, January 2017 , ISSN (Online): 23197064

[11] Katsaridis V, Papagiannaki C, Aimar E. Curative embolization of cerebral arteriovenous malformations (AVMs) with Onyx in 101 patients. Neuroradiology. 2008;50:589-597. doi: 10.1007/s00234-008-0382-X

[12] Sirakov S., Popivanov P. , Sirakov A. , Sirakova K. Endovascular Embolisation of a Complex Arteriovenous Malformation International Journal of Science and Research (IJSR), Volume 6 Issue 4, April 2017 , ISSN (Online): 2319-7064

[13] Sirakov S., Sirakov A., Minkin K. Endovascular Embolization of High-Risk ArteriovenousMalformation - International Journal of Science and Research (IJSR), Volume 6 Issue 2, February 2017 , ISSN (Online): $1437-1441$

[14] Ros HS, Lichtenstein P, Bellocco R, et al. Increased risks of circulatory diseases in late pregnancy and puerperium. Epidemiology 2001;12:456-460

[15] Sirakov S. Kamenov B., Penkov M. , Romansky $\mathrm{K}$. Internal carotid artery blister aneurysm embolization Roentgenologia\&Radiologia 2015 , LIV: 184-186,

[16] Sirakov S. ,Hristov H. , Sirakov A. , Ninov K. Endovascular Embolization of a Spinal Arteriovenous Fistula International Journal of Science and Research (IJSR), Volume 6 Issue 2, February 2017 , ISSN (Online): 1216-1220

[17] Sirakov S. , Sirakov A., Preoperative endovascular embolization of juvenile nasopharyngeal angiofibroma International Journal of Science and Research (IJSR), Volume 6 Issue 2, February 2017 , ISSN (Online): 1434-1436 